\title{
Circulating Tumor Cells in Metastatic Breast Cancer: A Prognostic and Predictive Marker
}

Sayyed Farshid Moussavi-Harami

Kari B. Wisinski

David J. Beebe

Follow this and additional works at: https://aah.org/jpcrr

Part of the Oncology Commons

\section{Recommended Citation}

Moussavi-Harami S, Wisinski KB, Beebe DJ. Circulating tumor cells in metastatic breast cancer: a prognostic and predictive marker. J Patient Cent Res Rev. 2014;1:85-92. doi: 10.17294/2330-0698.1017

Published quarterly by Midwest-based health system Advocate Aurora Health and indexed in PubMed Central, the Journal of Patient-Centered Research and Reviews (JPCRR) is an open access, peer-reviewed medical journal focused on disseminating scholarly works devoted to improving patient-centered care practices, health outcomes, and the patient experience. 


\title{
Circulating Tumor Cells in Metastatic Breast Cancer: A Prognostic and Predictive Marker
}

\author{
Sayyed Farshid Moussavi-Harami, MS, ${ }^{1,3}$ Kari B. Wisinski, MD, ${ }^{2}$ David J. Beebe, PhD $^{1,2}$ \\ ${ }^{1}$ Department of Biomedical Engineering, University of Wisconsin, Madison, WI \\ ${ }^{2}$ University of Wisconsin Carbone Cancer Center, Madison, WI \\ ${ }^{3}$ Medical Scientist Training Program, University of Wisconsin, Madison, WI
}

\begin{abstract}
The role of circulating tumor cells (CTCs) as a marker for disease progression in metastatic cancer is controversial. The current review will serve to summarize the evidence on CTCs as a marker of disease progression in patients with metastatic breast cancer. The immunohistochemistry (IHC)based CellSearch ${ }^{\circledR}$ is the only FDA-approved isolation technique for quantifying CTCs in patients with metastatic breast cancer. We searched PubMed and Web of Knowledge for clinical studies that assessed the prognostic and predictive value of CTCs using IHC-based isolation.
\end{abstract}

The patient outcomes reported include median and Coxproportional hazard ratios for overall survival (OS) and progression-free survival (PFS). All studies reported shorter OS for CTC-positive patients versus CTC-negative. A subset of the selected trials reported significant lower median PFS for CTC-positive patients. The reported trials support the utility of CTC enumeration for patient prognosis. But further studies are required to determine the utility of CTC enumeration for guiding patient therapy. There are three clinical trials ongoing to test this hypothesis. These studies, and others, will further establish the role of CTCs in clinical practice. (J Patient-Centered Res Rev. 2014;1:85-92.)

\section{Keywords}

biomarker, advanced breast cancer, circulating tumor cells, progression, outcome

\section{Introduction}

Breast cancer is the leading non-skin cancer diagnosed in females in the United States, with more than 200,000 new cases reported per year. ${ }^{1}$ Metastatic breast cancer (MBC) can present at initial diagnosis or after recurrence. While

Correspondence: David J. Beebe, PhD

Wisconsin Institutes for Medical Research, 1111 Highland Avenue, Madison, WI 53705, Phone: 608-262-2260, Fax: 608-265-6905,

Email: djbeebe@wisc.edu treatments for $\mathrm{MBC}$ are not considered curative, development of targeted biologic therapies and chemotherapy have significantly increased survivals., ${ }^{2,3}$ Current prognostic factors for MBC include Eastern Cooperative Oncology Group patient performance status, the site of metastatic disease, the number of disease sites, estrogen receptor status, progesterone receptor status, human epidermal growth factor receptor-2 (HER2/neu) expression, progressionfree interval, prior adjuvant therapy, and prior therapy for $\mathrm{MBC}^{4-7}$ In addition to these initial tumor features, various techniques are used to measure tumor response or disease progression while on anticancer treatments. These include various imaging modalities that detect site of disease, quantify tumor volume, ${ }^{8,9}$ and detect glucose uptake. ${ }^{10-13}$ Unfortunately, imaging studies fail to capture tumor heterogeneity, are expensive and time consuming, and because they are done sporadically, may not provide timely detection of therapeutic resistance. ${ }^{14-16}$ Because of these shortcomings, various assays have been developed to measure blood-based biomarkers including CA15-3 and CA27.29, carcinoembryonic antigen (CEA) and CA-125. ${ }^{17-19}$ However, only $50 \%$ to $60 \%$ of MBCs have a positive tumor marker to follow, and prospective studies validating their clinical utility are still limited. ${ }^{20-23}$

More recently, circulating tumor cells (CTCs) isolated from blood have been tested as a new prognostic tool and as markers of disease progression. ${ }^{24-42}$ Using CTCs as a biomarker affords the advantage of capturing cells that are biologically relevant to the metastatic process. ${ }^{43,44}$ CTCs are a rare population of cells of epithelial origin detectable in the blood of cancer patients. ${ }^{24,26}$ The presence of CTCs in the blood was documented more than a century ago by T. R. Ashworth, an Austrian pathologist who first reported this type of cell. ${ }^{45}$ Through the years, researchers have used various techniques for isolating CTCs including microfluidics, ${ }^{46-50}$ antibody-coated magnetic beads combined with immunohistochemistry (IHC) ${ }^{27,51,52}$ and multiplex polymerase chain reaction (PCR). ${ }^{53-55}$ Using these techniques, researchers have reported worse 
prognoses with higher CTC counts in patients with breast, ${ }^{27-29,31,32,34,35,40,54,56-59}$ colon, $^{25,60,61}$ prostate ${ }^{30,46,62,63}$ and lung cancer. ${ }^{64-67}$

Currently, CellSearch ${ }^{\circledR}$ (Veridex LLC, Raritan, NJ) is the only U.S. Food and Drug Administration (FDA)-approved technique for quantifying CTCs in patients with metastatic cancer. The CellSearch ${ }^{\circledR}$ isolation is a multistep process involving an initial CTC enrichment stage using magnetic particles recognizing the epithelial cell adhesion molecule (EpCAM). This enrichment concentrates CTCs from 7.5 $\mathrm{ml}$ of blood to $300 \mu \mathrm{l}$. The cell concentrate is stained for epithelial cell markers (cytokeratin-8, -18, -19), nucleic acid dye 4, 2-diamidino-2-phenylindole dihydrochloride (DAPI), and a leukocyte-specific marker (CD45). The stained cells are imaged and analyzed using semiautomated image analysis. In this assay, a CTC is defined as a DAPI positive, cytokeratin positive and CD45 negative cell. The positive threshold is set at 5 CTCs per $7.5 \mathrm{ml}$ of blood. The positive selection using EpCAM-coated ferromagnetic beads enables binding of multiple ferromagnetic particles to a single cell through the use of biotin/avidin chemistry, thereby amplifying the magnetic load. This chemistry increases CTC capture and sensitivity, but leads to nonspecific binding to leukocytes. The cell isolate is stained, enabling one to distinguish CTCs from leukocytes and cell debris.

Independent research has previously validated the analytical performance of the CellSearch ${ }^{\circledR}$ system. $^{68}$ The inter- and intra-assay variability are very low at $<5 \%$. Furthermore, shipping and storage up to 72 hours has minimal effects on CTC detection, if samples are stored at room temperature. Longer durations of storage increase unassigned events, cells requiring identification by the user, and the time required for analysis. The recovery efficiency of cancer cell lines diluted in healthy blood is reported to be $80 \%{ }^{68}$

One limitation of the CellSearch ${ }^{\circledR}$ method is the positive selection of CTCs using EpCAM-antibody coated beads. While a significant portion $(80 \%-100 \%)$ of breast cancers express EpCAM, ${ }^{69-71}$ studies indicate lower EpCAM expression in CTCs and disseminated tumor cells. ${ }^{72}$ Furthermore, there is decreased EpCAM expression with epithelial-mesenchymal transition. ${ }^{73}$ This suggests that selection of CTCs based on EpCAM expression may reduce CTC capture. The avidin/biotin chemistry utilized by CellSearch ${ }^{\circledR}$ is designed to overcome this decrease in EpCAM antigen expression by amplifying the magnetic load per antigen.
A second weakness of CellSearch ${ }^{\circledR}$ is the use of specific cytokeratins to identify CTCs. Downregulation of cytokeratins occurs with epithelial-mesenchymal transformation. ${ }^{74,75}$ The possible reduction in expression of cytokeratins by CTCs is addressed in CellSearch ${ }^{\circledR}$ by using pan-cytokeratin antibodies.

In the 2007 American Society for Clinical Oncology (ASCO) ${ }^{20}$ update of recommendations for tumor biomarkers in breast cancer, the available evidence for CTC measurements in patients with advanced breast cancer was reviewed. The 2007 ASCO guidelines recommended against use of CTC measurements pending further evidence and validations. However, several studies regarding the role of CTCs as a prognostic factor or as a marker of disease progression have been published since the ASCO review. One metaanalysis has addressed the use of PCR-based techniques for quantifying the presence of CTCs as a biomarker. ${ }^{56}$ But PCR-based techniques fail to give information on the morphology and other features of the tumor cells present in the peripheral blood and there is no FDA-approved technology for PCR-based techniques (Table 1). No reviews or meta-analyses have addressed the use of IHC-based CTC isolation techniques as a marker for patients with metastatic breast cancer.

Table 1. Advantages and disadvantages of current CTC isolation techniques

\begin{tabular}{|l|l|l|l|}
\hline \multirow{4}{*}{ IHC-based } & Approach & Advantage & Disadvantage \\
\cline { 2 - 4 } & $\begin{array}{l}\text { Cell search } \\
\text { CellSearch } \\
\text { CTC chip } \\
\text { Filter-based } \mu \text { Cell } \\
\text { concentrator }\end{array}$ & $\begin{array}{l}\text { Cell morphology } \\
\text { Cell enumeration } \\
\text { Multiple stainings } \\
\text { Localization of } \\
\text { stainings }\end{array}$ & $\begin{array}{l}\text { Multistep } \\
\text { Positive selection } \\
\text { with EpCAM }\end{array}$ \\
\hline PCR-based & $\begin{array}{l}\text { CK19 } \\
\text { Mammoglobin }\end{array}$ & Multiplex & $\begin{array}{l}\text { High background } \\
\text { Cimited to CTC } \\
\text { specific markers } \\
\text { Low cell number } \\
\text { No cell enumeration }\end{array}$ \\
\hline
\end{tabular}

CEA, carcinoembryonic antigen; CTC, circulating tumor cell; CK19, cytokeratin-19; EpCAM, epithelial cell adhesion molecule; IHC, immunohistochemistry; PCR, polymerase chain reaction.

The current review will serve to summarize published articles addressing the use of IHC-based CTC isolation as a marker in patients with metastatic breast cancer. The aim of this review is to assist medical oncologists and oncology nurse practitioners in understanding the potential use of CTCs in clinical practice, and to provide guidance for future research needs on CTCs as a marker in patients with MBC. 


\section{Methods}

\section{Literature Search}

The databases PubMed and Web of Science were systematically searched for all relevant articles reporting human studies published from January 2001 to September 2013 (past 12 years). The Medical Subject Headings (MeSH terms)/keywords used included "circulating tumor cells," "neoplastic cells, circulating," "breast neoplasms" or "breast cancer," and "prognostic*" or "outcome*." Reviewed publications were limited to articles. The reference list was checked for relevant articles that contained retrospective or prospective studies of patients with metastatic breast cancer.

\section{Inclusion and Exclusion Criteria}

The search results were then screened according to the following inclusion criteria: (1) outcome measurements reported had to include either median progression-free survival (PFS) or overall survival (OS) or both; (2) measurements had to include CTC enumeration defined as EpCAM-positive, DAPI-positive, cytokeratin-positive and CD45-negative cells; (3) circulating tumor cells had to be isolated from venous blood.

Articles were excluded if they reported clinical trials involving patients that received surgery during the course of the study. The article search for this review did not include unpublished literature, conference abstracts, or dissertations. No language restrictions were placed on this search, but following the initial review of English abstracts, no nonEnglish articles were selected. The references of selected articles were searched by hand for additional studies, but no unique publications were identified by this search.

\section{Data Extraction}

The first author (FMH) screened and retrieved the literature list using the mentioned criteria. The reviewer (FMH) was not blinded to the article title or authors. The data extracted from each article included CTC characteristics, median PFS, and OS. Within the selected articles, radiologists were blinded to the patient clinical progression and CTC characteristics.

\section{Data Analysis}

The selected studies were assessed unblinded by the authors using the critical appraisal of prognostic test questionnaire from the Center for Evidence Based Medicine (CEBM) at University of Oxford (www.cebm.net). The critical appraisal questionnaire does not provide a numeric score, but it contains a set of questions appraising the validity of the clinical trial, with three possible answer options, "yes," "no" or "unclear." An article was included in this review if reviewers answered "no" or "unclear" to only one CEBM appraisal question and "yes" to all other appraisal questions (Table 2). Since the study appraisal did not provide a numeric value, intrarater reliabilities were not analyzed.

\section{Statistical Analysis}

We recorded the reported median and Cox hazard ratio values for PFS and OS, in addition to their $95 \%$ confidence intervals.

\section{Results}

The current review only included clinical studies that reported PFS, OS, or both in patients with MBC. The initial search with "breast neoplasms" and "neoplastic cells, circulating" or other keywords representing breast cancer and CTCs produced a broad selection of articles from PubMed and Web of Science. The additional keywords "outcome*" and "prognosis*" were added, producing 164 articles from PubMed and 41 from Web of Science (searched in September 2013). After further screening of the abstracts, 17 articles were selected based on the inclusion and exclusion criteria. The main reason for exclusion included: studies involving patients with nonmetastatic breast cancer, clinical trials using non-IHC based CTC isolation, and studies not reporting PFS or OS. From the selected articles, none were exluded based on their CEBM questionnaire.

All of the selected articles with the exception of one study used the FDA-approved CellSearch ${ }^{\circledR}$ technique for isolating CTCs (Table 2). While other approaches have been developed and tested in research settings, the articles reporting these techniques did not meet the inclusion and exclusion criteria for this review. Gradilone et al. ${ }^{54}$ reported the only study implementing a different CTC identification method. This study used magnetic bead selection coupled with multiplex PCR to study CTC gene expression of chemotherapy resistance proteins.

Studies using CellSearch ${ }^{\circledR}$ to enumerate CTCs reported differences in median PFS or OS at the cut-off of 5 CTCs/7.5 mL blood (Tables 3 and 4). ${ }^{27,29,31,32,34,35,57,76-80}$ All studies reported decreased OS of CTC-positive versus CTCnegative patients. These reported measurements included changes in median OS and the Cox proportional hazard ratio. A subset of the selected trials reported lower median PFS between CTC-positive and CTC-negative patients. One study reported a significant difference in OS between the CTC-positive and CTC-negative patients, but reported a limited difference in PFS. ${ }^{76}$ The inconsistency of OS and PFS in this trial may be due to the limitations of PFS as a marker for OS. 
Table 2. Summary of reviewed studies, isolation method and review based on Oxford prognostic checklist

\begin{tabular}{|c|c|c|c|c|c|c|}
\hline Author & Year & \# of participants & Method & Follow-up time & Oxf Prog checklist & Isolation method \\
\hline Cristofanilli et al. ${ }^{27}$ & 2004 & 177 & Prospective & 9 months & All yes & CellSearch \\
\hline Budd et al. ${ }^{35}$ & 2006 & 138 & Prospective & Median 28 months & All yes & CellSearch \\
\hline Hayes et al. ${ }^{29}$ & 2006 & 177 & Prospective & 30 months & All yes & CellSearch \\
\hline Cristofanilli et al. ${ }^{57}$ & 2007 & 151 & Retrospective & Median 12.7 months & $\begin{array}{l}\text { Yes, except patient } \\
\text { stage at enrollment } \\
\text { is not mentioned }\end{array}$ & CellSearch \\
\hline Nole et al. ${ }^{41}$ & 2008 & 60 & Prospective & Median 34 weeks & All yes & CellSearch \\
\hline De Giorgi et al. ${ }^{31}$ & 2009 & 115 & Retrospective & $\begin{array}{c}40 \text { months after mid- } \\
\text { therapy }\end{array}$ & $\begin{array}{c}\text { Yes, no separation } \\
\text { of other prognostic } \\
\text { groups }\end{array}$ & CellSearch \\
\hline Liu et al. ${ }^{34}$ & 2009 & 81 & Prospective & Median 13.3 & $\begin{array}{c}\text { Yes, no separation } \\
\text { of other prognostic } \\
\text { groups }\end{array}$ & CellSearch \\
\hline Bidard et al. ${ }^{37}$ & 2010 & $\begin{array}{c}67 \text { patients } \\
\text { (4 nonoperable } \\
\text { locoregional } \\
\text { relapse) }\end{array}$ & Prospective & Median 8.8 months & All yes & CellSearch \\
\hline De Giorgi et al. ${ }^{32}$ & 2010 & 195 & Retrospective & 36 months & All yes & CellSearch \\
\hline Botteri et al. ${ }^{59}$ & 2010 & 80 & Prospective & Median 28 months & All yes & CellSearch \\
\hline Gradilone et al. ${ }^{54}$ & 2011 & 42 & Prospective & Median 24 months & All yes & $\begin{array}{c}\text { EpCAM-coated } \\
\text { beads (CELLection } \\
\text { Dynabeads) + } \\
\text { Multiplex PCR }\end{array}$ \\
\hline Harkopf et al. ${ }^{36}$ & 2011 & 58 & Retrospective & Median 13.2 months & $\begin{array}{l}\text { Yes, except no } \\
\text { separation of } \\
\text { different prognostic } \\
\text { determinants }\end{array}$ & CellSearch \\
\hline Giuliano et al. ${ }^{33}$ & 2011 & 235 & Retrospective & Median 18 months & All yes & CellSearch \\
\hline Muller at al. ${ }^{76}$ & 2011 & 253 & Prospective & Median 11 months & All yes & CellSearch \\
\hline Pierga et al. ${ }^{80}$ & 2012 & 267 & Prospective & Median 14.9 months & All yes & CellSearch \\
\hline Giordana et al. ${ }^{77}$ & 2012 & 517 & Retrospective & Median 24.6 months & All yes & CellSearch \\
\hline Wallwiener et al. ${ }^{79}$ & 2013 & 486 & Prospective & Median 11.1 months & All yes & CellSearch \\
\hline
\end{tabular}

EpCAM, epithelial cell adhesion molecule; PCR, polymerase chain reaction.

Several studies compared CTC counts with imaging modalities including fluorodeoxyglucose positron emission tomography (PET) and computed tomography (CT) imaging. Multivariate analysis of CTC enumerations indicated that CTCs provide additional prognostic information that is unavailable with imaging studies. ${ }^{29,32,57}$ Furthermore, baseline CTC enumeration better predicted median OS compared to PET-based techniques. ${ }^{31}$ Interestingly, the CTC counts were dependent on the site of metastasis, in addition to the the level of metastatic involvement. For example, patients with bone and visceral metastases had higher CTC counts compared to patients with bone-only metastasis. ${ }^{32}$

Most studies did not control for type of anticancer therapy. The therapies used in the reviewed articles included various endocrine therapies targeting the hormone receptors, agents targeting the HER2 and vascular endothelial growth factor receptors, and traditional chemotherapy. In one reviewed study, ${ }^{37}$ the cut-off of 3 CTCs per $7.5 \mathrm{ml}$ of blood was associated with a shorter time-to-disease-progression in patients with $\mathrm{MBC}$ receiving the antiangiogenic drug bevacizumab. ${ }^{37}$ Angiogenesis is a necessary step for intravasation of CTCs into the blood; therefore, the lower cut-off in this study for CTC-positive samples may be due to the impairment of angiogenesis by bevacizumab. The ability of CTCs to predict a prognosis, independent of patient therapy, further supports their use as a biomarker.

In addition, multiple trials evaluated CTCs at specific study intervals, and reported significant differences in outcomes based on CTC status changes during treatment, suggesting the role of CTCs as a marker of disease progression. Hayes et al. reported similar median OS between baseline CTC negative participants and patients that converted from CTC positive to CTC negative during the study ${ }^{29}$ Furthermore, all studies reported that in response to therapy, there was a 
Table 3. Median progression free survival (PFS) values for CTC-positive and CTC-negative patients, and Cox proportional hazard ratios $(H R)$ based on univariate analysis

\begin{tabular}{|l|c|c|c|c|}
\hline Author & Year & $\begin{array}{c}\text { Median PFS } \\
\mathbf{C T C}<5, \mathbf{C T C} \geq \mathbf{5} \text { (month) }\end{array}$ & $\begin{array}{c}\text { 95\% CI PFS } \\
\mathbf{C T C}<5, \mathbf{C T C} \geq \mathbf{5} \text { (month) }\end{array}$ & Cox HR \\
\hline Cristofanilli27 & 2004 & $7.0,2.7$ & $(5.8-8.9),(2.1-4.4)$ & 1.76 \\
\hline Nole $^{41}$ & 2008 & $>11.5,5.1$ & $\mathrm{~N} / \mathrm{A}$ & 2.5 \\
\hline Liu $^{34}$ & 2009 & $5.1,3.2$ & $(3.1-6.7),(2.5-6.2)$ & 1.4 \\
\hline Gradilone $^{54}$ & 2011 & $16.3,9.2$ & $\mathrm{~N} / \mathrm{A}$ & $\mathrm{N} / \mathrm{A}$ \\
\hline Giuliano $^{33}$ & 2011 & $12.0,7.0$ & $(9.6-14.3),(5.8-8.2)$ & 1.72 \\
\hline Muller $^{76}$ & 2011 & $10.9,9.3$ & $(9.4-12.5),(7.8-10.9)$ & $\mathrm{N} / \mathrm{A}$ \\
\hline Pierga $^{80}$ & 2012 & $16.0,8.2$ & $\mathrm{~N} / \mathrm{A}$ & 1.9 \\
\hline Giordano $^{77}$ & 2012 & $6.3,5.8$ & $(5.3-7.3),(5.0-6.7)$ & 1.23 \\
\hline Wallwiener $^{79}$ & 2013 & $7.6,4.8$ & $(5.9-9.3),(3.9-5.6)$ & 1.82 \\
\hline
\end{tabular}

Cl: confidence interval; CTC: circulating tumor cell.

Table 4. Median overall survival (OS) for CTC-positive and CTC-negative patients, and Cox proportional hazard ratio (HR) based on univariate analysis

\begin{tabular}{|c|c|c|c|c|c|}
\hline Author & Year & $\begin{array}{c}\text { Median OS } \\
\text { CTC }<5, \text { CTC } \geq 5 \text { (month) }\end{array}$ & $\begin{array}{c}95 \% \mathrm{CI} \text { OS } \\
\text { CTC }<5, \text { CTC } \geq 5 \text { (month) }\end{array}$ & Cox HR & 95\% Cl (Cox HR) \\
\hline Cristofanillii' & 2004 & $>18,10.1$ & $\mathrm{~N} / \mathrm{A},(6.2-14.6)$ & 4.26 & $\mathrm{~N} / \mathrm{A}$ \\
\hline Budd $^{35}$ & 2006 & $22.6,8.5$ & $(20.1$ to $>25.0),(6.2-15.1)$ & 3.18 & $(2.0-5.9)$ \\
\hline Hayes $^{29}$ & 2006 & $21.9,10.9$ & $(20.1$ to $>25),(6.4-15.1)$ & 2.45 & $(1.6-3.7)$ \\
\hline Cristofanillij7 & 2007 & $29.3,13.5$ & $\mathrm{~N} / \mathrm{A}$ & 2.3 & $(1.3-4.1)$ \\
\hline De Giorgi ${ }^{31}$ & 2009 & $28.0,6.2$ & (17.2 to >18.2), (5.9-15.7) & 1.3 & $(0.7-2.6)$ \\
\hline De Giorgi ${ }^{32}$ & 2010 & $34.8,18.5$ & $(23.5$ to $>40),(13.6-85.0)$ & 2.2 & $(1.4-3.5)$ \\
\hline Hartkopft ${ }^{36}$ & 2011 & $>24,9.8$ & N/A, (7.3-12.3) & N/A & $\mathrm{N} / \mathrm{A}$ \\
\hline Giuliano $^{33}$ & 2011 & $40.1,21.9$ & $(34.9-45.4),(15.6-28.4)$ & 2.5 & $(1.6-3.9)$ \\
\hline Muller $^{76}$ & 2011 & $20.1,14.0$ & $(18.8-21.5),(12.8-21.5)$ & 2.48 & $(1.5-4.4)$ \\
\hline Piergra $^{80}$ & 2012 & $>33,19.8$ & $\mathrm{~N} / \mathrm{A}$ & 2.4 & $(1.1-5.4)$ \\
\hline Giordano $^{77}$ & 2012 & $32.4,18.3$ & $(25.3-39.5),(15.5-21.1)$ & 2.1 & $(1.7-2.7)$ \\
\hline Wallwiener ${ }^{79}$ & 2013 & $>23,18.01$ & $\mathrm{~N} / \mathrm{A}$ & 4.8 & $(2.9-7.8)$ \\
\hline
\end{tabular}

Cl: confidence interval; CTC: circulating tumor cell.

significant drop in absolute CTC counts and the number of CTC positive patients. ${ }^{27,31,36}$ Based on these earlier results, a clinical trial was initiated by the Southwest Oncology Group (SWOG S0500; NCT00382018, www.clinicaltrials.gov) to test whether women with MBC and with elevated CTCs after one course of first-line chemotherapy would benefit from a switch in chemotherapy. This would differ from the current clinical standards, because the switch in therapy would occur prior to identifiable clinical progression based on standard clinical or imaging criteria. The preliminary results of this trial have now been reported and the primary endpoint of improved median OS was not met. ${ }^{81}$ In addition to the SWOG trial, a second trial (CirCè01) has been initiated to further characterize the role of CTCs as predictive markers of response to therapy. The CirCè01 is a phase III multicenter clinical trial using changes in CTC counts to guide the choice of third-line chemotherapy for MBC. In this trial, CTCs will be measured prior to the addition of a new chemotherapy drug and, if there is little change in CTC counts after two weeks, a new chemotherapy will be initiated (NCT01349842). The final results from these trials will serve to determine the utility of changes in CTC enumeration on guiding patient therapy, and will better establish the role of CTCs in clinical practice.

\section{Conclusion}

The discovery of circulating tumor cells and the development of different isolation methods has led to an expanding area of research. The prognostic value of baseline CTCs using the Veridex method at the defined 5 cells $/ \mathrm{mL}$ cutoff in metastatic breast cancer is clear. Published studies have correlated CTC counts with MBC to tumor burden, PET and CT-based 
staging, site of metastasis, level of metastatic involvement, OS and PFS.

Despite the prognostic significance of CTCs, their role as a predictive marker remains unknown. Randomized, controlled clinical trials that include therapeutic arms dependent on changes in CTC enumeration are required to establish the usefulness of this biomarker in managing patient care. The final results of the SWOG-S0500 and CirCè01 trials will serve to establish the role of CTCs as markers for quantifying disease response to therapy. At this time, routine clinical use as a predictive marker is not recommended.

An advantage of IHC-based CTC isolation techniques is the ability to quantify the expression and activity of specific biologic receptors. For example, some previous studies have quantified HER2, estrogen-receptor and progesteronereceptor expression in CTCs. ${ }^{82}$ It would be important to correlate the biomolecular characteristics of CTCs with patient outcome, and to utilize this information for designing therapeutic trials. A recently initiated clinical trial (DETECT III) plans to use CTC HER2 status in patients with metastatic breast cancer to guide therapy. In this trial, patients with HER2-negative tumor but HER2-positive CTCs will receive lapatinib with standard therapy or standard therapy alone. The estimated primary completion date for this trial is March 2016 with the primary outcome measure of PFS (NCT01619111). This trial will determine the utility of CTC biomolecular signatures for guiding patient therapy.

CTC analysis is limited by the availability of current isolation technologies and their cost. The development of other CTC isolation techniques including PCR and microfluidic-based methods can address these shortcomings. ${ }^{46-48,50,56,83}$ The ability to isolate CTCs at multiple points of treatment by simple blood draw is an important advantage of CTCs in comparison to biopsy and imaging techniques. Currently, various tumor markers, for example, CEA, CA15-3 and CA27.29, are used to assess response to therapy. The addition of CTC enumeration to a panel that includes these tumor markers can increase their overall sensitivity and specificity. Compared to the tumor markers, CTCs can potentially provide multiple biological measurements including expression of hormone receptors, HER2, insulin growth factor receptor, and the receptors kinase activity. To better measure these biological markers in a single CTC, further advances in single-cell analysis are required. This would fulfill the promise of CTC as a "liquid biopsy" of the tumor. But even with the evidence supporting the role of CTCs as a marker of disease, there are a subset of CTC negative MBC patients with poor outcomes.
Therefore, further research is required to understand the limitations of CTCs as a biomarker of disease progression. In conjunction with clinical trials, controlled biologic experiments are required to establish the relevance of CTCs to disease spread.

Treatment of patients with metastatic breast cancer requires a fine balance between administering therapies to control the malignancy with the goal of improving cancer-related symptoms and complications as well as survival, but at the same time limiting the negative impact on quality of life from the treatments. Often, clinicians are faced with the challenge of determining whether the treatment is benefiting the patient using limiting information derived from the patient's symptoms, exam and basic laboratory results. Newer tools are clearly needed to aid in this decision making. Circulating tumor cells have the potential to be a noninvasive, early predictive biomarker to aid clinicians in their goal of maximizing benefit and limiting harms to patients with advanced breast cancer in the future.

\section{Acknowledgments}

We thank Dr. Arthur H. Cash for his assistance with the review edits. We thank Mr. Benjamin P. Casavant for his assistance. Sayyed Farshid Moussavi-Harami, MS, was supported by NIH grants 1UL1RR025011, 9U54TR000021, and 5R01EB010039. David J. Beebe, PhD, was supported by DOD PCRP Idea Award (W81XWH-09-1-0192). Kari B. Wisinski, MD, was supported by NIH P30 CA014520.

\section{Conflicts of Interest}

David J. Beebe, PhD, has an ownership interest in BellBrook Labs LLC.

\section{References}

1. Jemal A, Bray F, Center MM, Ferlay J, Ward E, Forman D. Global cancer statistics. CA Cancer J Clin. 2011;61:69-90.

2. Chia SK, Speers CH, D'Yachkova Y, et al. The impact of new chemotherapeutic and hormone agents on survival in a populationbased cohort of women with metastatic breast cancer. Cancer. 2007;110:973-9.

3. Gennari A, Conte P, Rosso R, Orlandini C, Bruzzi P. Survival of metastatic breast carcinoma patients over a 20-year period: a retrospective analysis based on individual patient data from six consecutive studies. Cancer. 2005;104:1742-50.

4. Kalaja VV. Recurrent or metastatic breast cancer: ESMO clinical recommendations for diagnosis, treatment and follow-up. Ann Oncol. 2007;18 Suppl 2:ii9-11.

5. Beslija S, Bonneterre J, Burstein HJ, et al. Third consensus on medical treatment of metastatic breast cancer. Ann Oncol. 2009;20:1771-85.

6. Fitzgibbons PL, Page DL, Weaver D, et al. Prognostic factors in breast cancer. College of American Pathologists Consensus Statement 1999. Arch Pathol Lab Med. 2000;124:966-78.

7. Lester SC, Bose S, Chen YY, et al. Protocol for the examination of specimens from patients with invasive carcinoma of the breast. Arch Pathol Lab Med. 2009;133:1515-38.

8. Eisenhauer EA, Therasse P, Bogaerts J, et al. New response evaluation criteria in solid tumours: revised RECIST guideline (version 1.1). Eur J Cancer. 2009;45:228-47. 
9. Schwartz LH, Bogaerts J, Ford R, et al. Evaluation of lymph nodes with RECIST 1.1. Eur J Cancer. 2009;45:261-7.

10. Ben-Haim S, Israel O. Breast cancer: role of SPECT and PET in imaging bone metastases. Semin Nucl Med. 2009;39:408-15.

11. Constantinidou A, Martin A, Sharma B, Johnston SR. Positron emission tomography/computed tomography in the management of recurrent/metastatic breast cancer: a large retrospective study from the Royal Marsden Hospital. Ann Oncol. 2011;22:307-14.

12. Morris PG, Ulaner GA, Eaton A, et al. Standardized uptake value by positron emission tomography/computed tomography as a prognostic variable in metastatic breast cancer. Cancer. 2012;118:5454-62.

13. Pan L, Han Y, Sun X, Liu J, Gang H. FDG-PET and other imaging modalities for the evaluation of breast cancer recurrence and metastases: a meta-analysis. J Cancer Res Clin Oncol. 2010;136: 1007-22.

14. Nowell PC. The clonal evolution of tumor cell populations. Science. 1976;194:23-8.

15. Talmadge JE, Wolman SR, Fidler IJ. Evidence for the clonal origin of spontaneous metastases. Science. 1982;217:361-3.

16. Simmons C, Miller N, Geddie W, et al. Does confirmatory tumor biopsy alter the management of breast cancer patients with distant metastases? Ann Oncol. 2009;20:1499-504.

17. Ebeling FC, Schmitt UM, Untch M, et al. Tumour markers CEA and CA 15-3 as Prognostic factors in breast cancer--univariate and multivariate analysis. Anticancer Res. 1999;19:2545-50.

18. Ebeling FG, Stieber P, Untch M, et al. Serum CEA and CA 15-3 as prognostic factors in primary breast cancer. $\mathrm{Br} J$ Cancer. 2002;86:1217-22.

19. Sturgeon CM, Duffy MJ, Stenman UH, et al. National Academy of Clinical Biochemistry laboratory medicine practice guidelines for use of tumor markers in testicular, prostate, colorectal, breast, and ovarian cancers. Clin Chem. 2008;54:e11-79.

20. Harris L, Fritsche H, Mennel R, et al. American Society of Clinical Oncology 2007 update of recommendations for the use of tumor markers in breast cancer. J Clin Oncol. 2007;25:5287-312.

21. Hayes DF, Zurawski VR, Jr., Kufe DW. Comparison of circulating CA15-3 and carcinoembryonic antigen levels in patients with breast cancer. J Clin Oncol. 1986;4(10):1542-50.

22. Hogan-Ryan A, Fennelly JJ, Jones M, Cantwell B, Duffy MJ. Serum sialic acid and CEA concentrations in human breast cancer. $\mathrm{Br}$ J Cancer. Apr 1980;41:587-92.

23. Tormey DC, Waalkes TP. Clinical correlation between CEA and breast cancer. Cancer. 1978;42:1507-11.

24. Maestro LM, Sastre J, Rafael SB, et al. Circulating tumor cells in solid tumor in metastatic and localized stages. Anticancer Res. 2009;29:4839-43.

25. Sastre J, Maestro ML, Puente J, et al. Circulating tumor cells in colorectal cancer: correlation with clinical and pathological variables. Ann Oncol. 2008;19:935-8.

26. Allard WJ, Matera J, Miller MC, et al. Tumor cells circulate in the peripheral blood of all major carcinomas but not in healthy subjects or patients with nonmalignant diseases. Clin Cancer Res. 2004; 10:6897-904.

27. Cristofanilli M, Budd GT, Ellis MJ, et al. Circulating tumor cells, disease progression, and survival in metastatic breast cancer. $N$ Engl J Med. 2004;351:781-91.

28. Cristofanilli M, Hayes DF, Budd GT, et al. Circulating tumor cells: a novel prognostic factor for newly diagnosed metastatic breast cancer. J Clin Oncol. 2005;23:1420-30.

29. Hayes DF, Cristofanilli M, Budd GT, et al. Circulating tumor cells at each follow-up time point during therapy of metastatic breast cancer patients predict progression-free and overall survival. Clin Cancer Res. 2006;12:4218-24.
30. Danila DC, Heller G, Gignac GA, et al. Circulating tumor cell number and prognosis in progressive castration-resistant prostate cancer. Clin Cancer Res. 2007;13:7053-8.

31. De Giorgi U, Valero V, Rohren E, et al. Circulating tumor cells and [(18)F]fluorodeoxyglucose positron emission tomography/computed tomography for outcome prediction in metastatic breast cancer. J Clin Oncol. 2009;27:3303-11.

32. De Giorgi U, Valero V, Rohren E, et al. Circulating tumor cells and bone metastases as detected by FDG-PET/CT in patients with metastatic breast cancer. Ann Oncol. 2010;21:33-9.

33. Giuliano M, Giordano A, Jackson S, et al. Circulating tumor cells as prognostic and predictive markers in metastatic breast cancer patients receiving first-line systemic treatment. Breast Cancer Res. 2011;13:R67.

34. Liu MC, Shields PG, Warren RD, et al. Circulating Tumor Cells: A Useful Predictor of Treatment Efficacy in Metastatic Breast Cancer. J Clin Oncol. 2009;27:5153-9.

35. Budd GT, Cristofanilli M, Ellis MJ, et al. Circulating tumor cells versus imaging--predicting overall survival in metastatic breast cancer. Clin Cancer Res. 2006;12:6403-9.

36. Hartkopf AD, Wagner P, Wallwiener D, Fehm T, Rothmund R. Changing levels of circulating tumor cells in monitoring chemotherapy response in patients with metastatic breast cancer. Anticancer Res. 2011;31:979-84.

37. Bidard FC, Mathiot C, Degeorges A, et al. Clinical value of circulating endothelial cells and circulating tumor cells in metastatic breast cancer patients treated first line with bevacizumab and chemotherapy. Ann Oncol. 2010;21:1765-71.

38. Bidard FC, Vincent-Salomon A, Sigal-Zafrani B, et al. Prognosis of women with stage IV breast cancer depends on detection of circulating tumor cells rather than disseminated tumor cells. Ann Oncol. 2008;19:496-500.

39. Bauernhofer T, Zenahlik S, Hofmann G, et al. Association of disease progression and poor overall survival with detection of circulating tumor cells in peripheral blood of patients with metastatic breast cancer. Oncol Rep. 2005;13:179-84.

40. Nakamura S, Yagata H, Ohno S, et al. Multi-center study evaluating circulating tumor cells as a surrogate for response to treatment and overall survival in metastatic breast cancer. Breast Cancer. 2010;17:199-204.

41. Nole F, Munzone E, Zorzino L, et al. Variation of circulating tumor cell levels during treatment of metastatic breast cancer: prognostic and therapeutic implications. Ann Oncol. 2008;19:891-7.

42. Dawood S, Broglio K, Valero V, et al. Circulating tumor cells in metastatic breast cancer from prognostic stratification to modification of the staging system? Cancer. 2008;113:2422-30.

43. Jiang WG, Martin TA, Mansel RE. Molecular detection of micrometastasis in breast cancer. Crit Rev Oncol Hematol. 2002;43:13-31.

44. Jiang WG, Puntis MC, Hallett MB. Molecular and cellular basis of cancer invasion and metastasis: implications for treatment. Br J Surg. 1994;81:1576-90.

45. Ashworth TR. A case of cancer in which cells similar to those in the tumors were seen in the blood after death. Aust Med J. 1869;14:146-9.

46. Nagrath S, Sequist LV, Maheswaran S, et al. Isolation of rare circulating tumour cells in cancer patients by microchip technology. Nature. 2007;450:1235-9.

47. Warrick J, Casavant B, Frisk M, Beebe D. A microfluidic cell concentrator. Anal Chem. 2010;82:8320-6.

48. Stott SL, Hsu CH, Tsukrov DI, et al. Isolation of circulating tumor cells using a microvortex-generating herringbone-chip. Proc Natl Acad Sci U S A. 2010;107:18392-7.

49. Stott SL, Lee RJ, Nagrath S, et al. Isolation and characterization of circulating tumor cells from patients with localized and metastatic prostate cancer. Sci Transl Med. 2010;2:25ra23. 
50. Issadore $\mathrm{D}$, Chung $\mathrm{J}$, Shao $\mathrm{H}$, et al. Ultrasensitive clinical enumeration of rare cells ex vivo using a micro-hall detector. Sci Transl Med. 2012;4:141ra192.

51. Gross HJ, Verwer B, Houck D, Hoffman RA, Recktenwald D. Model study detecting breast cancer cells in peripheral blood mononuclear cells at frequencies as low as 10(-7). Proc Natl Acad Sci USA. 1995;92:537-41.

52. Witzig TE, Bossy B, Kimlinger T, et al. Detection of circulating cytokeratin-positive cells in the blood of breast cancer patients using immunomagnetic enrichment and digital microscopy. Clin Cancer Res. 2002;8:1085-91.

53. Gradilone A, Gazzaniga P, Silvestri I, et al. Detection of CK19, CK20 and EGFR mRNAs in peripheral blood of carcinoma patients: correlation with clinical stage of disease. Oncol Rep. 2003;10: 217-22.

54. Gradilone A, Naso G, Raimondi C, et al. Circulating tumor cells (CTCs) in metastatic breast cancer (MBC): prognosis, drug resistance and phenotypic characterization. Ann Oncol. 2011;22:86-92.

55. Martin KJ, Graner E, Li Y, et al. High-sensitivity array analysis of gene expression for the early detection of disseminated breast tumor cells in peripheral blood. Proc Natl Acad Sci U S A. 2001;98: 2646-51.

56. Zhao S, Liu Y, Zhang Q, et al. The prognostic role of circulating tumor cells (CTCs) detected by RT-PCR in breast cancer: a meta-analysis of published literature. Breast Cancer Res Treat. 2011;130:809-16.

57. Cristofanilli M, Broglio KR, Guarneri V, et al. Circulating tumor cells in metastatic breast cancer: biologic staging beyond tumor burden. Clin Breast Cancer. 2007;7:471-9.

58. Munzone E, Botteri E, Sandri MT, et al. Prognostic value of circulating tumor cells according to immunohistochemically defined molecular subtypes in advanced breast cancer. Clin Breast Cancer. 2012;12:340-6.

59. Botteri E, Sandri MT, Bagnardi V, et al. Modeling the relationship between circulating tumour cells number and prognosis of metastatic breast cancer. Breast Cancer Res Treat. 2010;122:211-7.

60. Rahbari NN, Aigner M, Thorlund K, et al. Meta-analysis shows that detection of circulating tumor cells indicates poor prognosis in patients with colorectal cancer. Gastroenterology. 2010;138:1714-26.

61. Barreto G, Neve R, Shrikhande SV, Shukla PJ. Role of circulating tumour cells in predicting recurrence after excision of primary colorectal carcinoma (Br J Surg 2007;94:96-105). Br J Surg. 2007;94:644; author reply 644-5.

62. Scher HI, Jia X, de Bono JS, et al. Circulating tumour cells as prognostic markers in progressive, castration-resistant prostate cancer: a reanalysis of IMMC38 trial data. Lancet Oncol. 2009;10:233-9.

63. Shaffer DR, Leversha MA, Danila DC, et al. Circulating tumor cell analysis in patients with progressive castration-resistant prostate cancer. Clin Cancer Res. 2007;13:2023-9.

64. Naito T, Tanaka F, Ono A, et al. Prognostic impact of circulating tumor cells in patients with small cell lung cancer. $J$ Thorac Oncol. 2012;7:512-9.

65. Hou JM, Krebs MG, Lancashire L, et al. Clinical significance and molecular characteristics of circulating tumor cells and circulating tumor microemboli in patients with small-cell lung cancer. $J$ Clin Oncol. 2012;30:525-32.

66. Krebs MG, Hou JM, Sloane R, et al. Analysis of circulating tumor cells in patients with non-small cell lung cancer using epithelial marker-dependent and -independent approaches. J Thorac Oncol. 2012; 7:306-15.

67. Krebs MG, Sloane R, Priest L, et al. Evaluation and prognostic significance of circulating tumor cells in patients with non-small-cell lung cancer. J Clin Oncol. 2011;29:1556-63.
68. Riethdorf S, Fritsche H, Muller V, et al. Detection of circulating tumor cells in peripheral blood of patients with metastatic breast cancer: a validation study of the CellSearch system. Clin Cancer Res. 2007;13:920-8.

69. Went PT, Lugli A, Meier S, et al. Frequent EpCam protein expression in human carcinomas. Hum Pathol. 2004;35:122-8.

70. Momburg F, Moldenhauer G, Hammerling GJ, Moller P. Immunohistochemical study of the expression of a Mr 34,000 human epithelium-specific surface glycoprotein in normal and malignant tissues. Cancer Res. 1987;47:2883-91.

71. Packeisen J, Kaup-Franzen C, Knieriem HJ. Detection of surface antigen 17-1A in breast and colorectal cancer. Hybridoma. 1999; 18:37-40.

72. Rao CG, Chianese D, Doyle GV, et al. Expression of epithelial cell adhesion molecule in carcinoma cells present in blood and primary and metastatic tumors. Int J Oncol. 2005;27:49-57.

73. Jojovic M, Adam E, Zangemeister-Wittke U, Schumacher U. Epithelial glycoprotein-2 expression is subject to regulatory processes in epithelial-mesenchymal transitions during metastases: an investigation of human cancers transplanted into severe combined immunodeficient mice. Histochem J. 1998;30:723-9.

74. Woelfle U, Sauter G, Santjer S, Brakenhoff R, Pantel K. Downregulated expression of cytokeratin 18 promotes progression of human breast cancer. Clin Cancer Res. 2004;10:2670-4.

75. Willipinski-Stapelfeldt B, Riethdorf S, Assmann V, et al. Changes in cytoskeletal protein composition indicative of an epithelialmesenchymal transition in human micrometastatic and primary breast carcinoma cells. Clin Cancer Res. 2005;11:8006-14.

76. Muller V, Riethdorf S, Rack B, et al. Prospective evaluation of serum tissue inhibitor of metalloproteinase 1 and carbonic anhydrase IX in correlation to circulating tumor cells in patients with metastatic breast cancer. Breast Cancer Res. 2011;13:R71.

77. Giordano A, Giuliano M, De Laurentiis M, et al. Circulating tumor cells in immunohistochemical subtypes of metastatic breast cancer: lack of prediction in HER2-positive disease treated with targeted therapy. Ann Oncol. 2012;23:1144-50.

78. Giordano A, Egleston BL, Hajage D, et al. Establishment and validation of circulating tumor cell-based prognostic nomograms in first-line metastatic breast cancer patients. Clin Cancer Res. 2013;19:1596-602.

79. Wallwiener M, Hartkopf AD, Baccelli I, et al. The prognostic impact of circulating tumor cells in subtypes of metastatic breast cancer. Breast Cancer Res Treat. 2013;137:503-10.

80. Pierga JY, Hajage D, Bachelot T, et al. High independent prognostic and predictive value of circulating tumor cells compared with serum tumor markers in a large prospective trial in first-line chemotherapy for metastatic breast cancer patients. Ann Oncol. 2012;23:618-24.

81. Smerage JB, Barlow WE, Hayes DF, et al. SWOG S0500 - A randomized phase III trial to test the strategy of changing therapy versus maintaining therapy for metastatic breast cancer patients who have elevated circulating tumor cell (CTC) levels at first follow-up assessment. (abstr.) Cancer Res. 2013;73:S5-07.

82. Hayashi N, Nakamura S, Tokuda Y, et al. Prognostic value of HER2positive circulating tumor cells in patients with metastatic breast cancer. Int J Clin Oncol. 2012;17:96-104.

83. Lang JM, Casavant BP, Beebe DJ. Circulating tumor cells: getting more from less. Sci Transl Med. 2012;4:141ps113.

(C) 2014 Aurora Health Care, Inc. 